\title{
Morfometria, uso e cobertura do solo como indicadores de enchentes e inundações na Bacia do Rio do Prata, Ilha do Maranhão*
}

\section{Danyella Vale Barros, Quésia Duarte da Silva1, Estevânia Cruz Teixeira, Cristiane Mouzinho Costa, Ricardo Gonçalves Santana}

Universidade Estadual do Maranhão (UEMA). Departamento de História e Geografia. Grupo de Pesquisa Geomorfologia e Mapeamento. Cidade Universitária Paulo VI, S/N. Balsas. São Luís-MA (CEP 65055-310). E-mail: quesiaduartesilva@hotmail.com.

Resumo. As enchentes e inundações são fenômenos naturais distintos que fazem parte da dinâmica hidrológica de uma bacia hidrográfica, que pode apresentar ou não atributos físicos que a tornem mais suscetível à ocorrência desses eventos. No entanto, fatores externos como o uso e cobertura do solo, podem ter influência direta na intensificação da ocorrência e consequências desses fenômenos. Partindo desses pressupostos, o trabalho em questão buscou analisar algumas variáveis morfométricas da Bacia Hidrográfica do Rio do Prata associadas às classes de uso e cobertura do solo, afim de se identificar à sujeição desta à ocorrência dos fenômenos de enchente e inundação. Para o alcance do objetivo, compartimentou-se a bacia em questão em quatro sub-bacias para melhor gerenciamento dos aspectos morfométricos, bem como atualizou-se o mapa de uso e cobertura do solo elaborado para a bacia estudada, a partir de trabalhos de campo e de classificação, por fim, definiu-se quatro parâmetros morfométricos, sendo: densidade de drenagem (Dd), índice de sinuosidade (Is), índice de circularidade (Ic) e fator de forma (Kf). Os parâmetros morfométricos foram analisados juntamente com as classes de uso e cobertura do solo, onde se percebeu que a referida bacia apresenta-se em crescente processo de urbanização, com mais de $50 \%$ da área total urbanamente consolidada, além da retirada em grande escala da vegetação ainda existente na região. Constatou-se a instalação de diversas edificações nas planícies fluviais, em seus mais variados segmentos, o que tem contribuído diretamente para ocorrência dos eventos em questão. Identificou-se ainda que a sub-bacia três apresenta maior sujeição aos fenômenos de enchentes e inundações, seja pelo uso ou pela morfometria. Concluiu-se que apesar das características morfométricas apontarem a Bacia Hidrográfica do Rio Prata com média a alta sujeição, o uso inadequado do solo tem sido o fator deflagrador dos problemas supracitados.

Palavras-chave: Parâmetros morfométricos; Uso e cobertura do solo; Enchentes e inundações; Bacia Hidrográfica do Rio do Prata.
Recebido:

29/07/2016

Aceito:

29/09/2016

Publicado:

30/09/2016

Acesso Aberto

Artigo completo

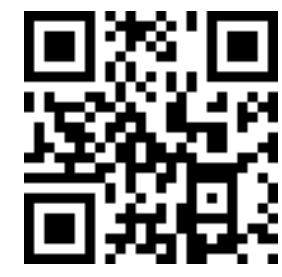

ORCID

(ㄱ) 0000-0002-7659-658X Danyella Vale Barros 0000-0003-0526-5940 Quésia Duarte da Silva (D) 0000-0001-8716-2392 Estevânia Cruz Teixeira (1) 0000-0002-5892-4877 Cristiane Mouzinho Costa

(D) 0000-0002-6611-0451

Ricardo Gonçalves

Santana

*Apresentado no V Congresso Brasileiro de Educação Ambiental Aplicada e Gestão Territorial, Fortaleza/CE, 8 a 11/06/2016. 
Abstract. Morphometry, use and soil cover as indicators of flooding and inundation in the River Prata Basin, Island of Maranhão. The floods and inundation are different natural phenomena that are part of the hydrological dynamics of the river basin, which may or may not have physical attributes that make them more susceptible to these events. However, external factors such as land use and land cover, can have a direct influence on the intensification of the occurrence and consequences generated by these phenomena. Based on these assumptions, the work in question sought to analyze the physical attributes of the River Prata Basin associated with the use of classes and soil cover in order to identify the subject of this the occurrence of flood and flood phenomena. For the purpose of reach compartmentalized to bowl in four sub-basins for better management of morphometric and updated to the use map and land cover prepared for the basin from work field and classification of the basin, eventually defined four morphometric parameters being: drainage density (DD), sinuosity index (is), circularity index (Ic) and form factor (Kf). The morphometric parameters were analyzed with the use of classes and soil cover, where it was noticed that the basin is presented in growing urbanization, with over $50 \%$ of urbanely consolidated total area, in addition to large-scale withdrawal the still existing vegetation in the region. Found that the installation of several buildings in the river plains in its various segments, which has directly contributed to the occurrence of the events in question. Identified himself even three sub-basin is more subject to the phenomena of floods and flooding, either by use or by morphometry. It was concluded that despite the morphometric characteristics present in River Prata Basin with medium to high subjection, improper land use has been the triggering factor of the above problems.

Keyword: Morphometric parameters; Use and land soil; Floods and inundation; Prata River Basin.

\section{Introdução}

A relação sociedade/natureza é uma das questões que mais representa o século $\mathrm{XXI}$, tendo em vista que este é marcado pelo crescente processo de urbanização, que vem se consolidando de maneira desordenada década após década.

O surgimento das cidades e a expansão desordenada da mancha urbana têm provocado diversos problemas de ordem física, social, econômica e cultural. Segundo Scarlato e Pontin (1999), as cidades são as estruturas materiais mais complexas que o ser humano já construiu e correspondem a um meio radicalmente transformado. A população urbana da sociedade brasileira aumentou rapidamente a partir da década de 1950, em um ritmo mais acelerado que o do crescimento populacional total, demonstrando assim, o processo de urbanização em curso.

Segundo Jorge (2011), o processo de urbanização brasileira têm se caracterizado pela apropriação do mercado imobiliário das melhores áreas da cidade e pela ausência, quase completa, de áreas urbanizadas destinadas à moradia popular, levando a população de baixa renda a buscar alternativas de moradia, ocupando áreas ambientalmente frágeis. Com a expansão deste processo, os recursos hídricos têm se tornado alvo fácil da intervenção antrópica. $\mathrm{O}$ crescimento acelerado da população e sua concentração em algumas porções do território, no caso as cidades, têm intensificado esta interferência, pois, além das necessidades básicas 
da sociedade, outras foram surgindo como: a geração de energia elétrica, o controle das enchentes, o aumento de área para ocupação e entre outros.

Evidentemente 0 crescimento urbano traz consigo diversos problemas ambientais, dentre eles, a compactação e impermeabilização dos solos, com a consequente diminuição da infiltração e o aumento do escoamento superficial, que pode levar aos eventos de enchente e inundação. Logo, a análise do uso e cobertura do solo de uma bacia hidrográfica urbana é fundamental, pois permite a observação das intervenções e impactos antrópicos em sua área.

Sobre este assunto Botelho (2011) afirma que:

\begin{abstract}
$\mathrm{Na}$ busca de novos espaços de ocupação e, principalmente, na solução do problema das enchentes, o homem alterou profundamente os rios, tornando-os "urbanos". Tais alterações, no entanto marcadas, predominantemente, por obras estruturais e mecânicas nos cursos d'água, levaram ao surgimento de problemas ambientais que, em verdade, não eram novos, ao contrário, já eram bem conhecidos: enchentes, destruição de casas e patrimônios, propagação de doenças de veiculação hídrica, surgimento de focos de vetores e perdas de vidas humanas (Botelho, 2011, p. 76).
\end{abstract}

O uso e cobertura do solo tem sido na maioria dos casos o agente deflagrador dos eventos de enchentes e inundações nas bacias hidrográficas urbanas brasileiras, porém existem condições físicas/ geomorfológicas que podem torná-la naturalmente suscetível a ocorrência desses fenômenos. Segundo Florenzano (2008), atualmente a morfodinâmica e a morfologia, campos da ciência geomorfológica, tem uma aplicação mais direta nos estudos ambientais voltados para o planejamento do uso da terra, e por isso estão sendo as variáveis mais estudadas no campo geomorfológico.

Os estudos morfológicos dividemse em morfográficos e morfométricos. Este último refere-se às variáveis quantitativas, também conhecidas como parâmetros morfométricos. Algumas das variáveis físicas podem ser expressas através desses parâmetros, os quais podem ser considerados como indicadores dos fenômenos de enchentes e inundações.

A correlação entre os parâmetros morfométricos e o uso e cobertura do solo permitem ao pesquisador estabelecer o grau das intervenções humanas na área estudada, através da associação da suscetibilidade natural da bacia e das intervenções externas.

As variáveis morfométricas auxiliam na identificação de áreas sujeitas a enchentes e inundações, e a partir do resultado obtido pode-se analisar mais claramente o uso dessas áreas. A identificação desses fenômenos pode ser realizada em gabinete, a partir da utilização de equações modelos que foram desenvolvidos ao longo do tempo por diversos pesquisadores. De acordo com Antoneli e Thomaz (2007), esses modelos fornecem subsídios para a análise morfométrica de determinada bacia hidrográfica.

Em relação aos fenômenos estudados, entende-se neste trabalho que os fenômenos de enchentes e inundações são distintos. Segundo Polivanov e Barroso (2011), o evento de inundação é o extravasamento do corpo hídrico para além dos limites dos canais fluviais principais, que também é um processo natural, que ocorre quando a vazão é superior à capacidade de descarga do canal.

Em relação às enchentes, Amaral e Ribeiro (2009) afirmam que as enchentes ou cheias são definidas pela elevação do nível d'água no canal de drenagem devido ao aumento da vazão, atingindo a cota máxima do canal, porém sem extravasar. Com relação a esta definição, Castro (2002, p. 48) corrobora que "nas enchentes, as águas elevam-se de forma paulatina e previsível, mantém-se em situação de cheia durante algum tempo e, a seguir, escoam-se gradualmente".

Logo, a distinção entre os fenômenos é clara, enquanto as enchentes ocorrem na área denominada leito maior dos canais fluviais (Christofoletti, 1980), podendo alcançar os equipamentos 
instalados neste setor, a inundação está relacionada ao transbordamento das águas fluviais, atingindo a planície de inundação, comumente denominada de várzea
(Figura 1). Em geral, estes fenômenos são intensificados em função do uso e cobertura do solo nas planícies de inundação e impermeabilizações ao longo das vertentes.

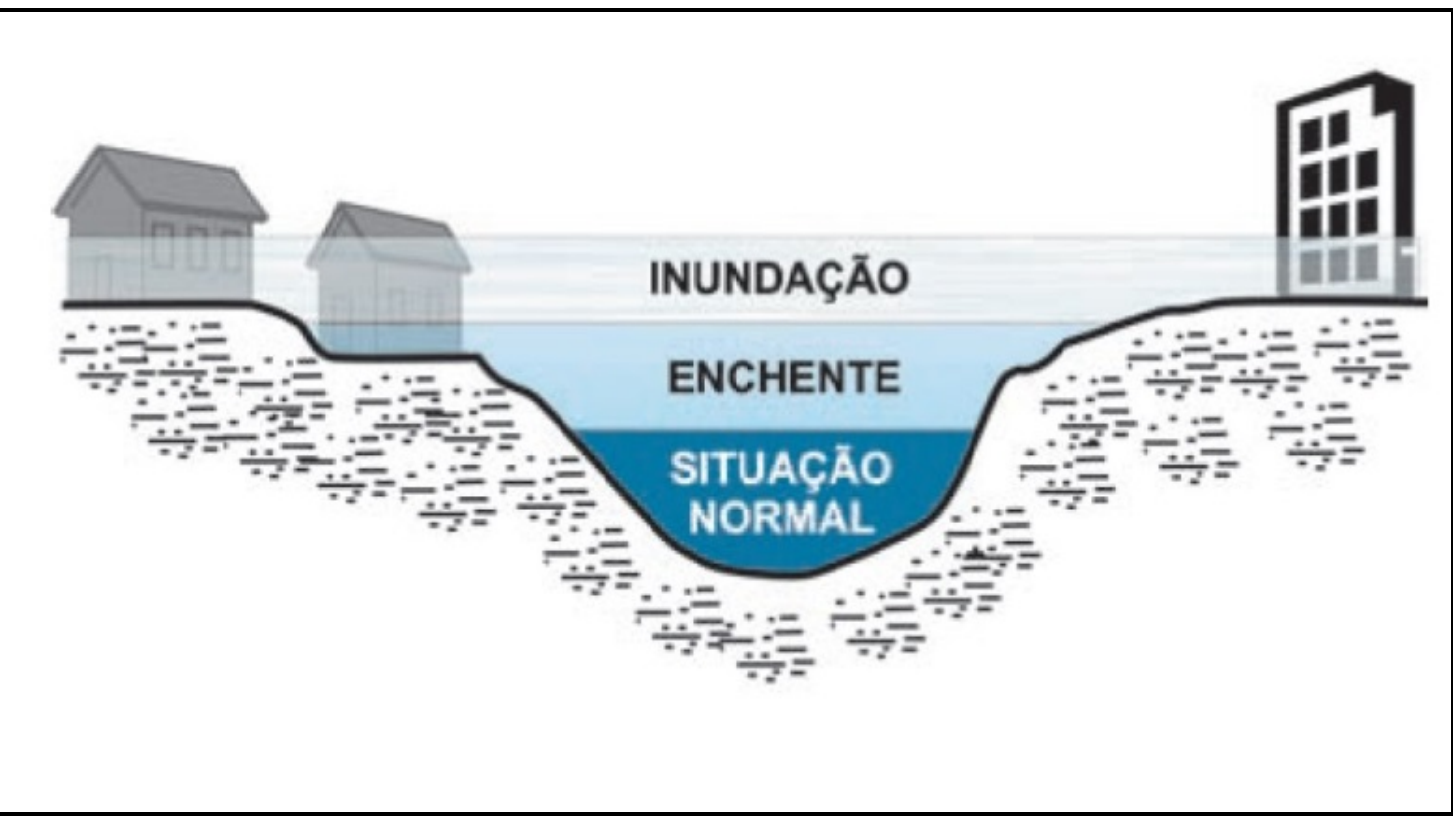

Figura 1. Perfil esquemático do processo de enchente e inundação. Fonte: Amaral e Ribeiro (2009).

Partindo desses pressupostos, o presente trabalho objetiva analisar a Bacia Hidrográfica do Prata e suas quatro subbacias, com o propósito de identificar as áreas mais sujeitas aos eventos de enchente e inundação a partir da análise morfométrica e do uso e cobertura do solo. Baseado em Villela e Mattos (1975), adotou-se a terminologia sujeição, para as áreas tendenciosas aos fenômenos supracitados.

Conforme Souza (2005) é comum o uso de correlações de parâmetros morfométricos para a determinação de suscetibilidade a enchentes e inundações em bacias hidrográficas. Uma vez apontadas pela morfometria às áreas sujeitas, analisa-se as mesmas a partir do uso predominante. Este trabalho está baseado em quatro parâmetros morfométricos: densidade de drenagem (Dd), índice de sinuosidade (Is), índice de circularidade (Ic) e fator de forma (Kf), a partir dos quais se identificou as sub-bacias mais sujeitas aos eventos supracitados.
Acredita-se que os documentos e trabalhos gerados no meio acadêmico relativo aos eventos de enchentes e inundações na Ilha do Maranhão, poderão ser utilizados como subsídio pela defesa civil municipal e outros órgãos públicos na mitigação desses problemas urbanos.

\section{Metodologia}

Para o alcance do objetivo, compartimentou-se a Bacia Hidrográfica do Prata em quatro sub-bacias para a realização da análise morfométrica, com o fim de identificar as áreas sujeitas aos eventos de enchente e inundação. Para a compartimentação adotou-se o conceito de bacia hidrográfica sendo uma área drenada por um canal principal e seus afluentes. Por esta razão, outros canais dentro da Bacia do Rio Prata não foram considerados subbacias, uma vez que não apresentam afluentes.

Para o mapeamento e extração dos parâmetros morfométricos utilizou-se 0 
programa ArcGIS da ESRI, versão 10.2, e toda a base cartográfica foi organizada através do Sistema de Coordenadas Geográficas, utilizando-se o Datum SIRGAS 2000. Utilizaram-se as cartas topográficas da DSG/ME-MINTER, cartas estas que estão disponibilizadas na página do ZEE-MA, Zoneamento EcológicoEconômico do Estado do Maranhão, folhas 7, 8 e 15, referentes à área de estudo, na escala de 1:10.000.

No programa ArcGIS delimitou-se as quatro Sub-Bacias do Prata, conforme a orientação dada pelos autores estudados, e mapeou-se os tipos de uso e cobertura do solo da bacia em questão, através de trabalhos de campo e da atualização do mapa de uso e ocupação da área de estudo elaborado por Nunes (2013). As categorias de uso e cobertura do solo utilizadas neste trabalho foram classificadas a partir dos dados de Maranhão (1998).

Em relação à morfometria, foram extraídos para cada uma delas, os dados referentes à área da bacia $(\mathrm{A})$, perímetro $(\mathrm{P})$, comprimento total dos canais (Lt), comprimento verdadeiro dos canais (Lv), comprimento em linha reta dos canais (Lv) e comprimento da bacia (L). Estes dados foram utilizados para o cálculo dos seguintes índices morfométricos: densidade de drenagem (Dd), índice de sinuosidade (Is), índice de circularidade (Ic) e fator de forma (Kf). Quanto à classificação desses parâmetros em relação aos eventos de enchentes e inundações utilizaram-se as propostas de Dury (1969, apud Christofoletti, 1980) e Silva (2012) com as adaptações consideradas necessárias para a Ilha do Maranhão. As sub-bacias foram numeradas de 1 a 4 para facilitar o trabalho de identificação das mesmas, uma vez que elas não apresentam toponímia.

\section{Resultados e discussão}

A Bacia Hidrográfica do Prata possui uma área de $6,27 \mathrm{~km}^{2}$ e está inserida no grupo das pequenas bacias da Ilha do Maranhão, ocupando uma área drenada nos Municípios de São Luís e de São José de Ribamar. Esta é uma bacia que se apresenta com crescente processo de urbanização, por se tratar de uma área litorânea e de fixação de residências de alto padrão.

Em relação às classes de uso e cobertura do solo, na bacia do Rio do Prata foram mapeadas nove classes (Figura 2), a saber: área urbanizada, área de ocupação, área de expansão, cordão arenoso, área de lazer, loteamento, manguezal, mata galeria e uma Reserva Particular do Patrimônio Natural (RPPN). As áreas de maior extensão são a área urbanizada e a área de loteamento, que ocupam, respectivamente, $51 \%$ e $26 \%$ da área total da bacia.

Segundo Maranhão (1998), as áreas urbanizadas são aquelas que apresentam maior intensidade de habitações, onde predominam as residências com padronização nas construções, advindas de financiamento oficial ou particular, e áreas de residências sólidas. Existem em média nesta bacia cerca de sete bairros consolidados, sendo eles Alonso Costa, Altos do Jaguarema, parte do Araçagy, Brisa do Mar, Divinéia e Sol e Mar.

As áreas de ocupação irregular são caracterizadas pela ocupação de locais onde a posse da terra se concretiza de fato, entretanto não significa a propriedade de direito. Os loteamentos, por sua vez, são áreas sem estrutura que se encontram ou não em processo de ocupação e tem definidos os traçados dos arruamentos. Sobre este assunto, a Lei $\mathrm{n}^{\circ} 6.766$, de 19 de dezembro de 1979 , no art. $2^{\circ}$, afirma:

$$
\begin{aligned}
& \S 1^{\circ} \text { Considera-se loteamento a } \\
& \text { subdivisão de gleba em lotes } \\
& \text { destinados a edificação, com abertura } \\
& \text { de novas vias de circulação, de } \\
& \text { logradouros públicos } \\
& \text { prolongamento, modificação ou } \\
& \text { ampliação das vias existentes. } \\
& {[\ldots]} \\
& \S 4^{\circ} \text { Consideram-se lotes o terreno } \\
& \text { servido de infraestrutura básica cujas } \\
& \text { dimensões atendam aos índices } \\
& \text { urbanísticos definidos pelo plano } \\
& \text { diretor ou lei municipal para a zona em } \\
& \text { que se situe. (Incluído pela Lei }{ }^{\circ} \\
& \text { 9.785, 29.01.99) (Brasil, 1999). }
\end{aligned}
$$

Segundo Maranhão (1998) as categorias de expansão são àquelas localidades consideradas "vagas" devido à 
inexistência e/ou previsão de ocupação e que se peculiarizam por se apresentarem, predominantemente revestidas por uma vegetação arbustivo/arbórea, assim como pelo fato de, na prática se constituir em reservas de expansão tanto em função do crescimento da demanda relativa ao uso residencial quanto daqueles a serem induzidos. Já as áreas de lazer referem-se ao tipo de ocupação estabelecida concernente a clube social ou camping (Maranhão, 1998).
Existe ainda a categoria de manguezal na área da bacia, que são ecossistemas resistentes à salinidade da água e do solo, e está presente em regiões tropicais e subtropicais de todo o planeta (Costa et al., 2006), o cordão arenoso que é um relevo constituído de detritos transportados pelo mar e pelos rios e que são acumulados geralmente ao longo da costa (Guerra e Guerra, 2008) e a mata galeria que acompanha naturalmente 0 curso dos rios e serve para mantê-los preservados.

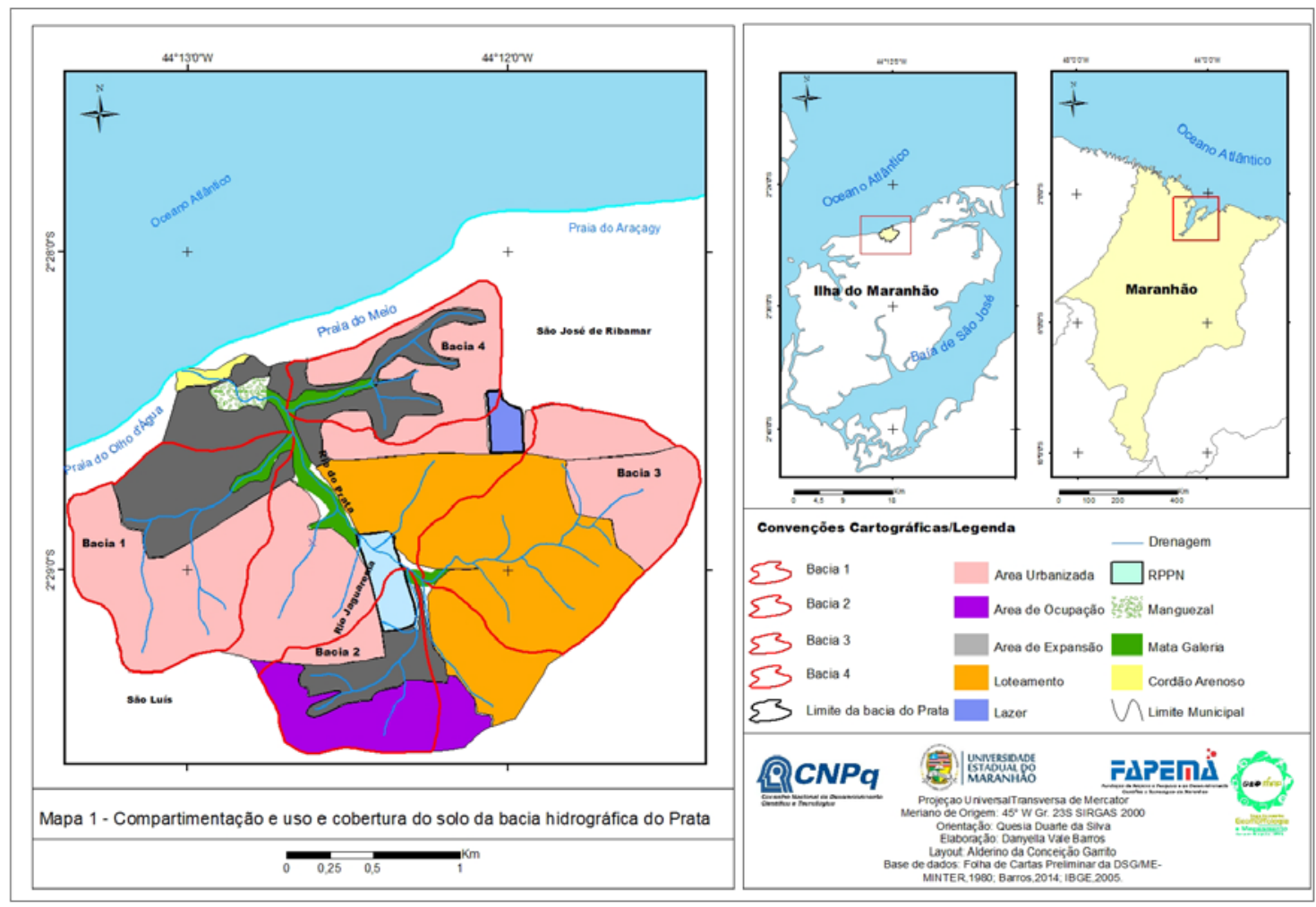

Figura 2. Compartimentação e uso e cobertura do solo da Bacia Hidrográfica do Prata, Ilha do Maranhão.

Por fim, tem-se a RPPN na bacia em questão, que tem sido utilizada como área de lazer pela população. A reserva ocupa aproximadamente 1,79\% da Bacia Hidrográfica do Rio Prata, o que corresponde a 0,11 $\mathrm{km}^{2}$. Apesar de a área ser de extrema importância na bacia estudada, à mesma não consegue absorver todos os impactos gerados pela atuação antrópica.
Analisando todas as sub-bacias do ponto de vista do uso e cobertura do solo pode-se apontar que na sub-bacia um é predominante o uso urbano e uma pequena percentagem do uso de expansão, a dois está situada em uma área de ocupação irregular e expansão, na três os usos predominantes são o loteamento e a urbanização e na sub-bacia quatro há presença da classe de urbanização e mata galeria. 
Em trabalhos de campo, constatouse nas quatro sub-bacias e na Bacia Hidrográfica do Prata de forma geral, a instalação de construções nos seus mais diversos segmentos na planície fluvial, desde casebres insalubres a condomínios de médio porte e estabelecimentos comerciais.

Quanto aos índices morfométricos analisados, Christofoletti (1980) afirma que a densidade de drenagem (Dd) foi definida inicialmente por Horton (1945) e é expressa pela relação entre o comprimento total dos cursos d'água de uma bacia e sua área total. Em relação a este parâmetro, quanto maior o seu resultado, menor é a capacidade de infiltração; valores baixos indicam que a região é mais favorável à infiltração, contribuindo com o lençol freático.

Neste trabalho, adotou-se a proposta de Silva (2012), que elaborou uma classificação regional para a Ilha do Maranhão, levando em consideração todas as bacias hidrográficas desta. Silva (2012) realizou análise estatística dos dados de densidade de drenagem para a referida Ilha, e as classes identificadas foram: de 0,59 a 0,98 - muito baixa; de 0,99 a 1,36 - baixa; de 1,37 a 1,75 - média; de 1,76 a 2,14 - alta; e de 2,15 a 2,53 - muito alta densidade de drenagem. Considera-se que, quanto maior a densidade de drenagem, mais rapidamente a água do escoamento superficial originado pela chuva chegará à jusante gerando altos picos de vazão o que favorece os fenômenos de enchente e inundação.

O índice de sinuosidade (Is) trata da relação entre o comprimento verdadeiro do canal com a distância vetorial (comprimento em linha reta) entre os dois pontos extremos do canal principal (Schum, 1963 apud Lana et al., 2001). Segundo Dury (1969, apud Christofoletti, 1980), os canais que apresentam índice de sinuosidade igual ou superior a 1,5 (adimensional) são considerados meandrantes e os canais com índice de sinuosidade menor que 1,5 são classificados como retos.

A sinuosidade é uma característica que controla a velocidade dos rios, logo, quanto mais retilíneo apresentarem-se os canais, maior será a probabilidade para a ocorrência de enchentes e inundações, uma vez que nestes canais ocorrerá maior velocidade do escoamento das águas.

O índice de circularidade (Ic) foi proposto inicialmente por Muller (1953) e Schumm (1956), citados por Antoneli e Thomaz (2007). Segundo a literatura especializada, quanto mais próximo de um chegar o resultado, mais circular será a bacia de drenagem e consequentemente, a bacia será mais suscetível às enchentes. Neste trabalho, baseado em Silva (2012), utilizou-se as seguintes classes quanto a este parâmetro: 0,36 a 0,50 - alongada, 0,51 a 0,75 - intermediária, e de 0,76 a 1 circular.

$\mathrm{O}$ fator de forma (Kf), por sua vez, é expresso pela relação entre a área total da bacia e seu comprimento ao quadrado. Silva (2012) propõe para a Ilha do Maranhão as seguintes classes: de 0,02 a 0,50 - alongada; de 0,51 a 0,75 - intermediária; e 0,76 a 1 forma circular. Conforme Villela e Mattos (1975), uma bacia com baixo fator de forma é menos sujeita aos fenômenos de enchente e inundação do que outra do mesmo tamanho com fator de forma alto.

Os parâmetros morfométricos encontrados estão apresentados na Tabela 1 nas cores verde, amarelo e vermelho, conforme a sujeição aos fenômenos supracitados. Para a densidade de drenagem, todas as sub-bacias são sujeitas, pois possuem muita alta densidade de drenagem. De acordo com a sinuosidade dos canais, todas apresentam sujeição por possuírem canais retos. Segundo o índice de circularidade, somente a sub-bacia três apresenta-se circular e consequentemente mais sujeita aos fenômenos estudados e para o fator de forma todas as sub-bacias são alongadas, apresentando baixa sujeição.

Analisando o quadro com todos os índices e as classes de uso e cobertura, observa-se que a Bacia Hidrográfica do Prata, como um todo, apresenta alta e média sujeição aos eventos de enchente e inundação. É uma bacia que se apresenta em crescente processo de urbanização, com uma área de loteamento muito extensa, onde a especulação imobiliária é muito grande. A vegetação da região tem sido retirada em grande escala por conta dessa especulação. 
As mais diversas modificações geradas pela ocupação do espaço urbano na bacia estudada são responsáveis por uma série de alterações no ciclo hidrológico. A impermeabilização dos terrenos através da construção de edificações e da pavimentação das vias de circulação são um dos principais responsáveis por essas alterações, além da quantidade excessiva de resíduos sólidos que são depositados de maneira inadequada nas vias públicas. Associado a estes fatores externos, a referida bacia apresenta características morfométricas, ou seja, naturais a ocorrência dos eventos de enchentes e inundações.

Tabela 1. Quadro de parâmetros morfométricos e resultados obtidos na análise das Sub-Bacias do Rio do Prata.

\begin{tabular}{|c|c|c|c|c|c|c|c|c|c|c|}
\hline \multicolumn{11}{|c|}{ Parâmetros morfométricos } \\
\hline Sub - bacia & $\begin{array}{c}\mathrm{A} \\
\left(\mathrm{km}^{2}\right)\end{array}$ & $\begin{array}{c}\mathrm{P} \\
(\mathrm{km})\end{array}$ & $\begin{array}{c}\mathrm{Lt} \\
(\mathrm{km})\end{array}$ & $\begin{array}{c}\mathrm{Lv} \\
\left(\mathrm{km}^{2}\right)\end{array}$ & $\begin{array}{c}\mathrm{Lr} \\
(\mathrm{km})\end{array}$ & $\begin{array}{c}\mathrm{L} \\
(\mathrm{km})\end{array}$ & $\begin{array}{c}\mathrm{Dd} \\
\left(\mathrm{km} / \mathrm{km}^{2}\right)\end{array}$ & $\begin{array}{c}\text { Is } \\
\text { (adimensional) }\end{array}$ & $\begin{array}{c}\text { Ic } \\
\text { (adimensional) }\end{array}$ & $\begin{array}{c}\mathrm{Kf} \\
\text { (adimensional) }\end{array}$ \\
\hline 1 & 1,19 & 4,70 & 2,98 & 1,83 & 1,55 & 1,68 & 2,50 & 1,18 & 0,67 & 0,42 \\
\hline 2 & 0,75 & 3,74 & 2,16 & 1,16 & 0,97 & 1,32 & 2,88 & 1,19 & 0,67 & 0,43 \\
\hline 3 & 1,50 & 4,91 & 3,56 & 1,55 & 1,39 & 1,73 & 2,37 & 1,11 & 0,78 & 0,50 \\
\hline 4 & 0,73 & 3,76 & 2,59 & 1,34 & 1,26 & 1,43 & 3,54 & 1,06 & 0,64 & 0,35 \\
\hline $\begin{array}{c}\text { Bacia } \\
\text { do Prata }\end{array}$ & 6,27 & 11,10 & 16,16 & 3,63 & 2,76 & 3,04 & 2,57 & 1,31 & 0,63 & 0,67 \\
\hline \multicolumn{11}{|c|}{$\begin{array}{l}\text { Siglas: } \mathbf{A}=\text { área } \mathbf{P}=\text { perímetro; } \mathbf{L t}=\text { comprimento total dos canais; } \mathbf{L v}=\text { comprimento verdadeiro dos canais; } \mathbf{L r}=\text { comprimento em linha } \\
\text { reta dos canais; } \mathbf{L}=\text { comprimento da bacia; } \mathbf{D d}=\text { Densidade de drenagem; } \mathbf{I s}=\text { Índice de sinuosidade; } \mathbf{I c}=\text { Índice de circularidade; } \\
\mathbf{K f}=\text { Fator de forma. }\end{array}$} \\
\hline & \multicolumn{3}{|c|}{ Alta sujeição } & Mé & ia sujeiç & & \multicolumn{3}{|c|}{ Baixa sujeição } & \\
\hline
\end{tabular}

Dentre as quatro sub-bacias estudadas a que apresenta maior sujeição aos fenômenos de enchente e inundação é de modo geral a três. Conforme os parâmetros morfométricos esta bacia possui uma alta velocidade no escoamento de suas águas (Is), bem como morfologicamente é circular (Ic), fator este que indica maior probabilidade da ocorrência dos eventos supracitados, além de apresentar baixa capacidade de infiltração.

Aliado a estes fatos indicados pela morfometria observou-se que nesta subbacia uma grande parte da cobertura vegetal foi retirada, há predominância das áreas de loteamento, uma parte significativa já esta com a urbanização consolidada, o que leva à compactação e impermeabilização do solo, à diminuição da infiltração, bem como já havia sido apontado pela morfometria, e o aumento do escoamento superficial, favorecendo ainda mais os fenômenos estudados.

\section{Considerações finais}

O uso e cobertura do solo da Bacia Hidrográfica do Prata é dividido predominantemente em duas classes: área urbanizada e loteamento, existindo poucas áreas verdes. Apesar de existir uma Reserva Particular de Patrimônio Natural - RPPN na área em questão, esta não é suficiente para absorver os impactos causados pela urbanização. Além deste fator, morfometricamente a bacia apresenta-se suscetível, segundo alguns parâmetros, a ocorrência dos eventos de enchente e inundação.

Baseado na análise morfométrica e nas classes de uso e cobertura do solo mapeadas na bacia, pôde-se concluir que a Bacia do Rio do Prata é sujeita aos fenômenos anteriormente citados, no entanto a sub-bacia três é mais sujeita que as demais aos fenômenos supracitados, sendo que esta apresenta muito alta 
densidade de drenagem, o que proporciona o encharcamento do solo mais rapidamente, fazendo com que esta diminua a sua capacidade de infiltração; seus canais retos proporcionam maior velocidade do escoamento superficial que foi produzido pela diminuição da capacidade de infiltração constata no índice anterior e sua forma circular, segundo o Ic, que também colabora para que haja um extravasamento mais veloz as águas fluviais nessa subbacia.

Atrelado aos fatores físicos, esta sub-bacia está inserida em uma área de crescente urbanização, em que grande parte da cobertura vegetal foi e está sendo retirada; 0 solo compactado e impermeabilizado tem auxiliado na geração excessiva do escoamento superficial.

Todos estes fatores analisados conjuntamente indicam que a sub-bacia três do Rio Prata é a mais sujeita aos fenômenos estudados neste trabalho. No entanto, vale ressaltar que a bacia hidrográfica como um todo, independentemente de sua compartimentação, tem apresentado anualmente casos de enchentes e inundações em toda a sua extensão areal, e estes têm afetado a população local. Apesar de a bacia estudada apresentar características morfométricas favoráveis aos eventos estudados neste trabalho, acredita-se que o uso inadequado do solo tem sido $\mathrm{o}$ fator deflagrador destes problemas, uma vez que muitas residências estão fixadas na planície fluvial, ambiente de ocorrência natural das enchentes.

\section{Declaração de conflito de interesses}

Os autores declaram não haver conflitos de interesses.

\section{Referências}

Amaral, R.; Ribeiro, R. R. Inundações e enchentes. In: Tominaga, L. K.; Santoro, J.; Amaral, R. (Orgs.). Desastres naturais: conhecer para prevenir. São Paulo: Instituto Geológico, 2009. p. 39-52.

Antoneli, V.; Thomaz, E. L. Caracterização do meio físico da Bacia do Arroio Boa Vista Guamiranga (PR). Caminhos de Geografia, v. 8, n. 21, p. 46-58, 2007. Disponível em: $<$ http://www.seer.ufu.br/index.php/caminhosdeg eografia/article/view/15570/8811>. Acesso em: 01 nov. 2013.

Botelho, R. G. M. Bacias hidrográficas urbanas. In: Guerra, A. J. T. (Org.). Geomorfologia urbana. Rio de Janeiro: Bertrand Brasil, 2011. p. 71-115.

Brasil. Leis, decretos, etc. Lei $\mathbf{n}^{\circ}$ 6.766, de 19 de dezembro de 1979. Dispõe sobre o parcelamento do solo urbano e dá outras providências. Disponível em: $<$ http://www.planalto.gov.br/ccivil_03/leis/L67 66.htm>. Acesso em: 22 mar. 2011.

Castro, A. L. C. Manual de desastres: desastres mistos. Brasília: Ministério do Interior, 2002.

Christofoletti, A. Geomorfologia. São Paulo: Edgard Blucher, 1980.

Costa， M. R. P.; Alcântara， E. H.; Amorim, A. J. E.; Mochel, F. R. Avaliação das potencialidades e fragilidades das áreas de manguezal para a implementação do ecoturismo usando ferramentas de sensoriamento remoto em Curupu-MA. Revista Caminhos da Geografia, v. 17, n. 17, p. 237-243, 2006. Disponível em: <http://www.seer.ufu.br/ index.php/caminhosdegeografia/article/view/15 409/8707>. Acesso em: 22 mar. 2011.

Florenzano, T. G. Cartografia. In: Florenzano, T. G. (Org.). Geomorfologia: conceitos e tecnologias atuais. São Paulo: Oficina de Textos, 2008. p. 105-128.

Guerra, A. T.; Guerra, A. J. T. Dicionário geológico-geomorfológico. 6 ed. Rio de Janeiro: Bertrand Brasil, 2008.

Horton, R. E. Erosional development of streams and their drainage basin: hidrographical approach to quantitative morphology. Geological Society of American Bulletin, v. 56, n. 3, p. 275-370, 1945.

Jorge, M. C. O. Geomorfologia urbana: conceitos, métodos e teorias. In: Guerra, A. T. (Org). Geomorfologia urbana. Rio de Janeiro: Bertrand Brasil, 2011. p. 117-145.

Lana, C. E.; Alves, J. M.; Castro, P. T. A. Análise morfométrica da Bacia do Rio do Tanque, MG - Brasil. Rem: Rev. Esc. Minas, v. 54, n. 2, p. 121-126, 2001. http://dx.doi.org/10.1590/S037044672001000200008

Maranhão. Estudo de ocupação espacial/uso e cobertura da terra. Macrozoneamento do Golfão Maranhense. Diagnóstico Ambiental da Microrregião da Aglomeração Urbana de São 
Luís e dos Municípios de Alcântara, Bacabeira e Rosário. São Luís: Sema/MMA/PNMA, 1998.

Müller, V. C. A quantitative geomorphology study of drainage basin characteristic in the Clinch Mountain Area. New York: Virginia and Tennesse Dept. of Geology, 1953.

Nunes, J. F. Análise comparativa do relevo de duas bacias hidrográficas da Ilha do Maranhão, considerando os índices de dissecação. São Luís, 2013. (Relatório de Iniciação Científica. Pesquisa em Geografia).

Polivanov, H.; Barroso, E. V. Geotecnia urbana. In: Guerra, A. T. (Org.). Geomorfologia urbana. Rio de Janeiro: Bertrand Brasil, 2011. p. 147-188.

Scarlato, F. C.; Pontin, J. A. O ambiente urbano. São Paulo: Atual, 1999.

Schumm, S. A sinuosity of alluvial rivers on the great plains. Bulletin of Geological Society of America, v. 74, n. 9, 1963.

Silva, Q. D. Mapeamento geomorfológico da Ilha do Maranhão. Presidente Prudente: Universidade Estadual de São Paulo, 2012. (Tese de Doutorado).

Souza, C. R G. Suscetibilidade morfométrica de bacias de drenagem ao desenvolvimento de inundações em áreas costeiras. Revista Brasileira de Geomorfologia, v. 6 n. 1, p. 4561, 2005.

Villela, S. M.; Mattos, A. Hidrologia aplicada. São Paulo: McGraw-Hill do Brasil, 1975.

Informação da Licença: Este é um artigo Open Access distribuído sob os termos da Licença Creative Commons AtribuiçãoSemDerivações-SemDerivados, que permite o download do trabalho e o compartilhamento desde que seja atribuído o devido crédito, mas sem que possa ser alterado de nenhuma forma ou utilizá-los para fins comerciais. 